\title{
STREPTOCOCCI ISOLATED FROM THE BLOODSTREAM AND GINGIVAL CREVICE OF MAN
}

\author{
I. CRAWford AND C. Russell* \\ Microbiology Department, Stepping Hill Hospital, Stockport, Cheshire, and \\ * Department of Oral Medicine, Turner Dental School, University of Manchester, \\ Manchester
}

\begin{abstract}
Summary. One hundred and twenty six strains of streptococci isolated from the bloodstreams of 123 hospital in-patients -55 with endocarditis-and 255 strains isolated from the gingival crevices of 66 volunteers were characterised. Species isolated were Streptococcus mitior, $S$. sanguis, undifferentiated viridans streptococci, $S$. salivarius, $S$. milleri, $S$. mutans, $S$. bovis and $S$. faecalis. There was no significant difference between the distribution of species in blood and in the gingival crevice. $S$. mitior and $S$. sanguis were found less frequently in blood than their presence in the gingival crevice would have suggested, whereas $S$. milleri was found more frequently. This may indicate that $S$. milleri is more invasive or that it enters the bloodstream from sources other than the gingival crevice.
\end{abstract}

\section{INTRODUCTION}

The role of streptococci in subacute bacterial endocarditis (SABE) has long been recognised (Libman and Celler, 1910). The changing microbial aetiology of the disease has been noted by many workers (Rabinovich et al., 1965; Lerner and Weinstein, 1966; Shinebourne et al., 1969; Finland and Barnes, 1970) but streptococci remain the largest single group of organisms associated with bacterial endocarditis. The mouth has been considered to be the principal portal of entry of streptococci into the bloodstream (Horder, 1909; Okell and Elliott, 1935; Bender and Pressman, 1945; McEntegart and Porterfield, 1949), and Korn and Schaffer (1962) have suggested that the gingival crevice is the most likely source.

Alpha haemolytic and non-haemolytic streptococci, amongst which at least five species can be identified (Carlsson, 1967 and 1968; Colman and Williams, 1972), comprise $15-28 \%$ of the bacterial flora of the gingival crevice (Gibbons et al., 1963; Williams, Pantalone and Sherris, 1976; Russell and Melville, 1978). The present survey was undertaken because the relative proportions of different species of streptococci in the gingival crevice are not well established (Burkiewicz and Kalowski, 1977).

A survey of streptococci isolated from the bloodstream in man was also undertaken 
to establish which species or subtypes were associated with streptococcal bacteraemia and SABE, and to compare their prevalence in blood with their prevalence in the gingival crevice.

\section{MATERIALS AND METHODS}

Bacterial strains. A total of 123 unselected strains of streptococci isolated from primary blood cultures were received from 26 hospital laboratories; each was accompanied by clinical details of the patient from whom the organism had been isolated. On receipt, each strain was subcultured on to two blood agar plates that were incubated for $48 \mathrm{~h}$ at $37^{\circ} \mathrm{C}$ in air plus $5-10 \%$ $\mathrm{CO}_{2}$. To confirm that the cultures were pure, 12 colonies randomly selected from the two plates were each seeded into $20 \mathrm{ml}$ of digest broth and incubated for $24 \mathrm{~h}$ at $37^{\circ} \mathrm{C}$. The 12 cultures were compared in eight screening tests: colonial appearance on Mitis-Salivarius agar and on blood agar; growth at $45^{\circ} \mathrm{C}$; aesculin hydrolysis; arginine hydrolysis; tolerance of $10 \%$ and $40 \%$ bile; and polysaccharide production from sucrose. Identical results from the 12 cultures indicated that the original culture was pure. Any variation in the results obtained with the 12 cultures separated them into different species or strains. One culture of each strain derived from each of the 123 original cultures was identified by physical, physiological and biochemical characteristics, including the screening tests that were repeated.

Strains from the gingival crevice were isolated from patients at the Manchester University Dental Hospital and from volunteers amongst the staff there and at Stepping Hill Hospital. Four broad groups of subjects were distinguished: healthy subjects; patients with obvious gingivitis (redness of the gingiva, possibly with bleeding on gentle probing); patients with early or moderate periodontitis (gingival redness with bleeding on gentle probing and pockets $2-4 \mathrm{~mm}$ deep); patients with severe periodontitis (gingival redness with bleeding on gentle probing associated with pockets $5 \mathrm{~mm}$ or more deep).

Supragingival plaque was removed from above the area to be sampled, and a sample of subgingival plaque obtained from the gingival crevice with a Number 7 dental curette. No attempt was made to standardise the sampling site nor the amount of subgingival debris removed. The position from which the sample was taken was recorded and the condition of the gum at that site was noted. The material from the crevice was homogenised in $5 \mathrm{ml}$ of sterile phosphate buffered saline (PBS) $p \mathrm{H} \mathrm{7.2}$. This was processed in the laboratory within $1 \mathrm{~h}$ to establish the identities and relative proportions of any streptococci present. Viable counts were performed by making tenfold dilutions of the homogenised gingival material in PBS ( 1 in 10 to 1 in $10^{4}$ ) and spreading $0 \cdot 1-\mathrm{ml}$ portions of each dilution across the surface of four media: Mitis-Salivarius agar, Mitis-Salivarius agar with sulphadimidine $1000 \mu \mathrm{g} / \mathrm{ml}$, Mitis-Salivarius agar with bacitracin $0.2 \mathrm{I} . \mathrm{U} . / \mathrm{ml}$ and sucrose $20 \%$ (w/v), and Kanamycin-Aesculin-Azide agar. After incubation at $37^{\circ} \mathrm{C}$ in air plus $5-10 \% \mathrm{CO}_{2}$ for $48 \mathrm{~h}$, the number of colonies of each type on each plate was counted. The dilution that gave $c .100$ colonies/plate was chosen for calculation of the number of $\mathrm{cfu} / \mathrm{ml}$. Each colony type was subcultured and identified.

Identification of streptococci was by the methods of Cowan (1974). The purity of all broth cultures was checked by terminal subculture on to blood agar. The identities of control strains of Streptococcus sanguis, S. mitior, S. salivarius and $S$. milleri were confirmed by the Streptococcal Reference Laboratory, Colindale.

Production of polysaccharide from sucrose. Dextran and levan were detected by adding 1-ml and $2.5-\mathrm{ml}$ volumes of $99.5 \%$ ethanol (Analar) to $1 \mathrm{ml}$ of the supernate from a $5 \%$ sucrose-broth culture (Carlsson, 1965) after incubation for 7 days at $37^{\circ} \mathrm{C}$. The formation of a floccular precipitate, encouraged by vigorous agitation for $30 \mathrm{~s}$ after the addition of the ethanol, indicated the presence of a polysaccharide- dextran when $1 \mathrm{ml}$ of ethanol was used and levan when $2.5 \mathrm{ml}$ was needed. The uncertainty of interpretation of a slight cloudiness that often appears when ethanol is added without agitation is eliminated by this procedure. $S$. sanguis (dextranproducer), $S$. salivarius (levan-producer) and $S$. mitior (non-producer) were used as controls. Lancefield grouping of isolates from blood cultures was performed with antisera for groups A-H and K-S inclusive (Wellcome Reagents Ltd, 303 Hither Green Lane, London SE13 6TL) by gel diffusion. Antigen extracts were prepared by autoclaving the centrifuged deposits of overnight cultures in Todd-Hewitt broth at $121^{\circ} \mathrm{C}$ for $10 \mathrm{~min}$. Plates of Oxoid ID (immunodiffusion) agar 
were poured to a depth of $2-3 \mathrm{~mm}$ in 9-cm-diameter petri dishes. Wells $2 \mathrm{~mm}$ in diameter were punched out of the agar in four separate clusters of five wells. Four of the wells filled with different antisera surrounded, at a distance of $3 \mathrm{~mm}$, a central well containing the antigen extract. Plates were examined after $24 \mathrm{~h}$ at room temperature. A positive reaction was a precipitation line between a central well and a surrounding well.

\section{RESULTS AND DISCUSSION}

\section{Identification of the isolates}

On the basis of criteria suggested by Parker and Ball (1976), developed from those of Colman and Williams (1972), 100 of the 126 isolates from blood cultures belonged to seven species (table I), and another 15 were $\beta$-haemolytic streptococci identifiable by the gel-diffusion test. The remainder comprised a $\beta$-haemolytic, non-groupable streptococcus and 10 isolates of unidentified viridans streptococci. Of the 255 gingival isolates, 207 belonged to eight species and 48 remained as unidentified viridans streptococci (table II). The properties of the isolates of $S$. mitior in the present series differed from those reported by Parker and Ball (1976) only in their greater tolerance of bile and their inability to produce acetoin and the results obtained with the $S$. sanguis isolates were in close agreement with their findings. The properties of $S$. milleri were similar to those reported by other workers. In contrast with our findings, Colman and Williams (1972) reported fermentation of raffinose or inulin by $S$. mutans strains less frequently. The strains of $S$. faecalis and the one strain of $S$. durans gave results typical of those species in biochemical tests. All the strains of $S$. bovis belonged to biotype I that produces dextran and ferments mannitol.

TABLE I

Identification of streptococci isolated from blood cultures

\begin{tabular}{|c|c|c|c|c|c|}
\hline \multirow[b]{2}{*}{ Species } & \multirow{2}{*}{$\begin{array}{c}\text { Total } \\
\text { number } \\
\text { of } \\
\text { isolates }\end{array}$} & \multicolumn{4}{|c|}{$\begin{array}{l}\text { Number of strains isolated } \\
\text { from patients with }\end{array}$} \\
\hline & & endocarditis & P.U.O. & $\begin{array}{l}\text { blood } \\
\text { dyscrasia }\end{array}$ & others \\
\hline S. mitior & 36 & 16 & 4 & 7 & 9 \\
\hline Dextran-positive $S$. mitior & 12 & 8 & 4 & 0 & 0 \\
\hline S. sanguis & 9 & 2 & 3 & 1 & 3 \\
\hline $\begin{array}{l}\text { Unidentified viridans } \\
\text { streptococci }\end{array}$ & 10 & 5 & 3 & 0 & 2 \\
\hline$S$. mutans & 8 & 6 & 1 & 0 & 1 \\
\hline S. milleri & 10 & 5 & $i$ & 0 & 4 \\
\hline S. salivarius & 5 & 4 & 0 & 0 & 1 \\
\hline$S$. faecalis & 12 & 4 & 3 & 1 & 4 \\
\hline S. bovis & 8 & 5 & 3 & 0 & 0 \\
\hline$\beta$-haemolytic streptococci & & & & & \\
\hline Lancefield group A & 4 & 0 & 2 & 0 & 2 \\
\hline Lancefield group B & 7 & 0 & 2 & 2 & 3 \\
\hline Lancefield group C & 2 & 1 & 0 & 1 & 0 \\
\hline Lancefield group $\mathrm{G}$ & 2 & i & 0 & 0 & 1 \\
\hline Not groupable & 1 & 0 & 0 & 0 & i \\
\hline Total & 126 & 57 & 26 & 12 & 31 \\
\hline
\end{tabular}

P.U.O. = pyrexia of undetermined origin. 
TABLE II

Identification of streptococci isolated from the gingival crevice

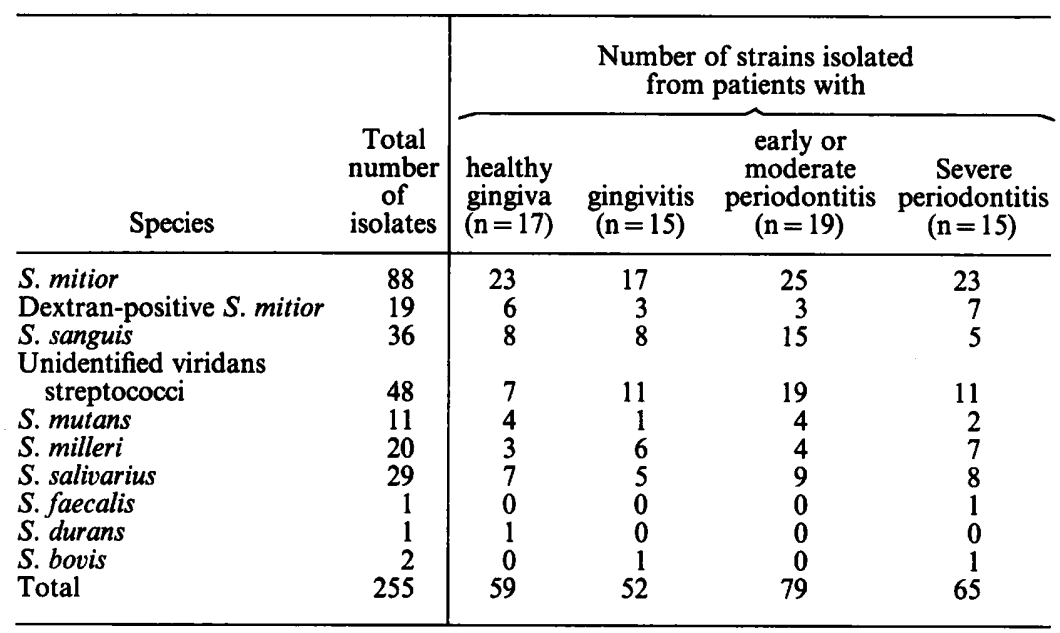

\section{Distribution of streptococci isolated from the blood stream}

$S$. mitior was the most common species isolated from each of the four clinical groups (table I) and was the species most often isolated from patients with endocarditis, an observation in agreement with those of Parker and Ball (1976) and Moulsdale, Eykyn and Phillips (1979). The lower incidence of $S$. sanguis in our studies than in that of Parker and Ball (1976) may be explained by differences in the populations sampled. The series of Parker and Ball may have included a disproportionately large number of "difficult" organisms referred for identification.

\section{Distribution of streptococci isolated from the gingival crevice}

The frequency with which the different species were encountered in each of the four clinical groups did not differ significantly. The most common species was $S$. mitior, followed by the unidentified viridans group and $S$. sanguis; $S$. salivarius was the fourth most frequent isolate.

Viable counts had been performed on every sample and it was possible to calculate the mean percentage of each species in the streptococcal flora of all 66 samples of gingival debris (table III). S. mitior was the commonest streptococcus in the gingival crevice, followed by $S$. sanguis and the unidentified viridans group. Although $S$. salivarius was present in 29 out of 66 samples, it always comprised $<1 \%$ of the flora in any sample, with the result that it comprised only $0.2 \%$ of the total flora of the 66 samples. S. faecalis, $S$. durans and $S$. bovis were isolated only infrequently. The figures in table III suggest that it is not merely the presence of an organism but its relative abundance in the gingival crevice that is reflected in its occurrence in the bloodstream. S. salivarius was present in $43.9 \%$ of the samples from the crevices but comprised only $0.2 \%$ of the total streptococcal flora and was isolated from blood cultures less often than $S$. mutans that was present in only $16.7 \%$ of samples from the 
TABLE III

Comparison of distribution of species isolated from blood cultures and from the gingival crevice

\begin{tabular}{|c|c|c|c|c|}
\hline \multirow[b]{2}{*}{ Species } & \multicolumn{2}{|c|}{$\begin{array}{l}\text { Percentage of isolates } \\
\text { from blood cultures } \\
\text { represented by the } \\
\text { given species }\end{array}$} & \multicolumn{2}{|c|}{$\begin{array}{l}\text { Distribution of streptococci in } \\
\text { the gingival crevice }\end{array}$} \\
\hline & $\begin{array}{c}\text { All } \\
\text { patients }\end{array}$ & $\begin{array}{l}\text { Patients with } \\
\text { endocarditis }\end{array}$ & $\begin{array}{l}\text { Percentage of } \\
\text { subjects from } \\
\text { whom the given } \\
\text { species was } \\
\text { isolated }\end{array}$ & $\begin{array}{l}\text { Percentage of the } \\
\text { total streptococcal } \\
\text { flora represented by } \\
\text { the given species }\end{array}$ \\
\hline S. mitior & $28 \cdot 6$ & $28 \cdot 1$ & $83 \cdot 3$ & $41 \cdot 8$ \\
\hline Dextran-positive $S$. mitior & $9 \cdot 5$ & $14 \cdot 0$ & $27 \cdot 3$ & $10 \cdot 4$ \\
\hline$S$. sanguis & 7.2 & 3.6 & $48 \cdot 5$ & $19 \cdot 0$ \\
\hline $\begin{array}{l}\text { Unidentified viridans } \\
\text { streptococci }\end{array}$ & $7 \cdot 9$ & $8 \cdot 8$ & $54 \cdot 5$ & $18 \cdot 2$ \\
\hline S. milleri & $7 \cdot 9$ & $8 \cdot 7$ & $30 \cdot 3$ & $5 \cdot 4$ \\
\hline S. mutans & $6 \cdot 3$ & $10 \cdot 5$ & $16 \cdot 7$ & $4 \cdot 5$ \\
\hline$S$. salivarius & 3.9 & $7 \cdot 0$ & $43 \cdot 9$ & $0 \cdot 2$ \\
\hline S. faecalis & $9 \cdot 5$ & $7 \cdot 0$ & $1 \cdot 5$ & 0.01 \\
\hline S. bovis & $6 \cdot 4$ & $8 \cdot 7$ & $1 \cdot 5$ & 0.2 \\
\hline S. durans & 0 & 0 & $1 \cdot 5$ & 0.2 \\
\hline$\beta$-haemolytic streptococci & & & & \\
\hline Lancefield group A & $3 \cdot 2$ & 0 & 0 & 0 \\
\hline Lancefield group B & 5.6 & 0 & 0 & 0 \\
\hline Lancefield group $\mathrm{C}$ & 1.6 & 1.8 & $\mathbf{0}$ & $\mathbf{0}$ \\
\hline Lancefield group G & 1.6 & 1.8 & 0 & 0 \\
\hline Ungroupable & 0.8 & 0 & 0 & 0 \\
\hline
\end{tabular}

crevices but comprised $4.5 \%$ of the total streptococcal flora. However, S. mutans was isolated from the blood of only two more patients with endocarditis than was $S$. salivarius, the difference may have no statistical significance. S. mitior and $S$. sanguis occurred less often in blood cultures than would have been expected from their presence in the gingival crevice but $S$. milleri was isolated more frequently from blood cultures than would have been expected and may be more virulent than $S$. mitior and $S$. sanguis or may enter the bloodstream from sources other than the gingival crevice. Several workers have emphasised the role of dextran-producing streptococci in SABE and this has led to investigations into the significance of dextran synthesis in the mechanism of adherence of streptococci to heart valves (Gould et al., 1975; Ramirez-Ronda, 1978 and 1980; Scheld, Valone and Sande, 1978). From our results, however, it can be seen that dextran-positive $S$. mutans and dextran-negative $S$. milleri were each isolated from blood samples more frequently than their abundance in the crevice would suggest. It should also be noted that dextran-negative $S$. mitior is the organism most frequently isolated from blood cultures from patients with endocarditis (Parker and Ball, 1976). This suggests that the ability of an organism to synthesise dextran is not essential for adherence and it seems likely that other factors are involved. Statistical analysis by Kendall Rank correlation tests and tests of frequency of occurrence by the chi-squared technique with $2 \times 2$ contingency tables or Fisher's exact probability tests showed no significant differences in the distribution of the biotypes of $S$. mitior or $S$. sanguis in blood and in the gingival crevice. 
Comparison of the distribution of streptococci isolated from the gingival crevice and from apical abscesses

A close correlation was found between the proportions of different streptococci isolated from apical abscesses reported by Wickremesinghe and Russell (1976) and the proportions of the same species in the flora of the gingival crevice in the present study. $S$. milleri was the exception; its frequency of isolation from apical abscesses was greater than expected from its occurrence as a proportion of the gingival streptococcal flora. Its frequency of isolation from apical abscesses did correlate, however, with the number of crevices from which it was isolated, irrespective of the proportion of the streptococcal flora that it represented in any given crevice. Its frequency of isolation from apical abscesses appeared to be closely related to its presence in the crevice which suggests that $S$. milleri is more virulent than other species; this conclusion is in agreement with the observations of Ball and Parker (1979). Statistical analysis again showed no significant differences in distribution of biotypes of $S$. mitior or $S$. sanguis in abscesses and in the gingival crevice.

\section{REFERENCES}

BALL, L. C. AND PARKer, M. T. 1979. The cultural and biochemical characters of Streptococcus milleri strains isolated from human sources. Journal of Hygiene, 82, 63-78.

Bender, I. B. AND Pressman, R. S. 1945. Factors in dental bacteraemia. Journal of the American Dental Association, 32, 836-853.

BURKIEWICZ, B. AND KALOWSKI, M. 1977. Streptococcal flora of normal and inflamed gingival pockets. Czasopismo Stomatologiczne, 30, 859-864. (in Polish)

CarLSSON, J. 1965. Zooglea-forming streptococci, resembling Streptococcus sanguis isolated from dental plaque in man. Odontological Review, 16, 348-358.

CARLSSON, J. 1967. Presence of various types of non-haemolytic streptococci in dental plaque, and in other sites of the oral cavity in man. Odontological Review, 18, 55-74.

Carlsson, J. 1968. A numerical taxonomic study of human oral streptococci. Odontological Review, 19, 137-160.

Colman, G. AND Williams, R. E. O. 1972. Taxonomy of some human viridans streptococci. In Streptococci and streptococcal diseases, recognition, understanding and management, edited by L. W. Wannamaker and J. M. Matsen, Academic Press, New York, pp. 281-299.

CowAN, S. T. 1974. Cowan and Steele's Manual for the identification of medical bacteria, 2nd ed., Cambridge University Press, Cambridge.

FINLAND, M. AND BARNES, M. W. 1970. Changing aetiology of bacterial endocarditis in the antibacterial era. Experiences at Boston City Hospital 1933-1965. Annals of Internal Medicine, 72, 341-348.

Gibbons, R. J., Socransky, S. S., Sawyer, S., Kapsimalis, B. and Macdonald, J. B. 1963. The microbiota of the gingival crevice area of man. II. The predominant cultivable organisms. Archives of Oral Biology, 8, 281-289.

Gould, K., Ramirez-Ronda, C. H., Holmes, R. K. AND Sanford, J. P. 1975. Adherence of bacteria to heart valves in vitro. Journal of Clinical Investigation, 56, 1364-1370.

HORDER, T. J. 1909. Infective endocarditis. Quarterly Journal of Medicine, 2, 289-324.

KORN, N. A. AND SCHAFFER, E. M. 1962. A comparison of the post-operative bacteraemias induced following different periodontal procedures. Journal of Periodontology, 33, 226-231.

LERNER, P. I. AND WeINSTEIN, L. 1966. Infective endocarditis in the antibiotic era. New England Journal of Medicine, 274, 199-206, 259-266, 388-393.

Libman, E. AND Celler, H. L. 1910. The etiology of subacute infective endocarditis. American Journal of Medical Science, 140, 516-527. 
MCENTEgart, M. G. AND PoRTerfield, J. S. 1949. Bacteraemia following dental extractions. Lancet, 2, 596-598.

McGowan, D. A. 1979. Infective endocarditis and dentistry. Dental Update, 6, 195-203.

Moulsdale, M. T., EyKyn, S. AND PHILlips, I. 1979. Infective endocarditis 1970-78: a review of 81 patients with particular reference to streptococci. In Pathogenic streptococci, edited by M. T. Parker, Reedbooks, Chertsey, pp. 229-231.

OKell, C. C. AND EllotT, S. D. 1935. Bacteraemia and oral sepsis, with special reference to the aetiology of subacute endocarditis. Lancet, 2, 869-872.

ParkeR, M. T. AND BALL, L. C. 1976. Streptococci and aerococci associated with systemic infection in man. Journal of Medical Microbiology, 9, 275-302.

Rabinovich, S., Evans, J., Smith, I. M. AND JaNUARY, L. E. 1965. A long term view of bacterial endocarditis, 337 cases 1924-1963. Annals of Internal Medicine, 63, 185-198.

RAMIREZ-RONDA, C. H. 1978. Adherence of glucan positive and glucan-negative streptococcal strains to normal and damaged heart valves. Journal of Clinical Investigation, 62, 805-814.

RAMIREZ-RoNDA, C. H. 1980. Effects of molecular weight of dextran on the adherence of Streptococcus sanguis to damaged heart valves. Infection and Immunity, 29, 1-7.

Russell, C. AND Melville, T. H. 1978. A review: Bacteria in the human mouth. Journal of Applied Bacteriology, 44, 163-181.

SCheld, W. M., VAlONE, J. A. AND SANDE, M. A. 1978. Bacterial adherence in the pathogenesis of endocarditis. Interaction of bacterial dextran, platelets and fibrin. Journal of Clinical Investigation, 61, 1394-1404.

Shinebourne, E. A., Cripps, C. M., Hayward, G. W. And Shooter, R. A. 1969. Bacterial endocarditis 1956-1965: Analysis of clinical features and treatment in relation to prognosis and mortality. British Heart Journal, 31, 536-542.

WiCKREMESINGHE, R. AND RusSELL, C. 1976. Viridans streptococci associated with periapical dental abscesses. Infection, 4, 196-203.

Williams, B. L., Pantalone, R. M. ANd Sherris, J. C. 1976. Subgingival microflora and periodontitis. Journal of Periodontal Research, 11, 1-18. 